\title{
¿Qué publicación reciente no me puedo perder?
}

\author{
Joaquin Tognelli \\ Miembro del Comité Editorial
}

Si bien existen varias publicaciones recientes que vale la pena mencionar, el siguiente trabajo es para destacar ya que nos obliga a repensar la estrategia multimodal del Cáncer de Recto:

MRI-Based Use of Neoadjuvant Chemoradiotherapy in Rectal Carcinoma: Surgical Quality and Histopathological Outcome of the OCUM TrialMartin E. Kreis, MD, Reinhard Ruppert, MD, Rainer Kube, MD, Joachim Strassburg, MD, Andreas Lewin, MD, Joerg Baral, MD, Christoph A. Maurer, MD, Joerg Sauer, MD, Gunther Winde, MD, Rena Thomasmeyer, MD, Sigmar Stelzner, MD, Cornelius Bambauer, MD, Soenke Scheunemann, MD, Axel Faedrich, MD, Theodor Junginger, MD, Paul Hermanek, MD, Susanne Merkel, $\mathrm{MD}$, and For the OCUM group. Ann Surg Oncol. 2020 Feb;27(2):417-427. doi: 10.1245/s10434-01907696-y. Epub 2019 Aug 14.

Actualmente varios grupos de investigación se enfocan en la reducción de la morbimortalidad producida por la sumatoria de la cirugía y la radioquimioterapia mediante la selección adecuada de pacientes en el tratamiento del Cáncer Rectal.

Presentaremos un trabajo multicéntrico, prospectivo y observacional, el más reciente del grupo Suizo-Alemán OCUM. Este evalúa la calidad de las cirugías realizadas y cuenta con el mayor número de pacientes enrolados hasta el momento $(n=875)$.

Teniendo en cuenta que el compromiso del margen de resección circunferencial es un factor de riesgo independiente para la Recurrencia Local, los autores dividieron a los pacientes en un grupo de "alto riesgo" y otro de "bajo riesgo” según los hallazgos de la Resonancia Magnética de Alta Resolución al momento del diagnóstico. El grupo de "alto riesgo" está compuesto por los pacientes con tumores a una distancia menor a $1 \mathrm{~mm}$ del margen de resec- ción circunferencial en recto medio o alto, tumores cT4 o cT3 de recto bajo. A este grupo se le indicó radioquimioterapia neoadyuvante de larga duración previa a la cirugía. El grupo de pacientes con tumores con margen de resección mayor a $1 \mathrm{~mm}$ o cT1 y cT2 de recto bajo fue considerado de "bajo riesgo" y se le realizó una Resección Total de Mesorrecto sin terapia previa. No tuvieron en cuenta a los ganglios mesorrectales afectados para la toma de decisiones.

El grupo de "bajo riesgo" conformó el 60,2\% de los pacientes incluidos en el protocolo. La resección fue R0 en el 98,3\% de los casos y el compromiso del margen de resección circunferencial fue negativo en el 95,1\%. Estos hallazgos ponen en evidencia, por un lado, la alta calidad de las cirugías realizadas y por el otro la confiabilidad de la RMN.

Es particularmente interesante que, de 600 pacientes con cáncer de recto medio o bajo estadio II o III, el 44,7\% no recibió tratamiento neoadyuvante, a diferencia de lo que hubiera sucedido de seguir las guías NCCN. Evitando así, sus efectos adversos.

Cabe destacar que el presente estudio es un análisis de outcomes secundarios de un estudio en curso, cuyos datos preliminares fueron publicados en 2018. En el mismo, se evidenció que la tasa de recurrencia local a los 3 y 5 años de seguimiento era de $1,3 \%$ y $2,7 \%$ respectivamente.

Estos resultados prometedores no se podrían lograr sin una excelente calidad en el análisis de las imágenes y en la performance quirúrgica, lo que nos genera el interrogante sobre la validez externa del trabajo. Sin embargo, estos resultados están respaldados por los previamente publicados en los estudios multicéntricos del grupo europeo (MERCURY) y del grupo canadiense (Quicksilver).

Esperamos ansiosamente leer sobre los resultados definitivos del OCUM group.

\section{Joaquin Tognelli}

tognelli.joaquin@gmail.com

Recibido: mayo de 2020. Aceptado: junio de 2020. 